\title{
Cross-sectional time trends in psychological and somatic health complaints among adolescents: a structural equation modelling analysis of 'Health Behaviour in School-aged Children' data from Switzerland
}

Dey, Michelle ; Jorm, Anthony F ; Mackinnon, Andrew J

DOI: https://doi.org/10.1007/s00127-015-1040-3

Posted at the Zurich Open Repository and Archive, University of Zurich ZORA URL: https://doi.org/10.5167/uzh-127363

Journal Article

Accepted Version

Originally published at:

Dey, Michelle; Jorm, Anthony F; Mackinnon, Andrew J (2015). Cross-sectional time trends in psychological and somatic health complaints among adolescents: a structural equation modelling analysis of 'Health Behaviour in School-aged Children' data from Switzerland. Social Psychiatry and Psychiatric Epidemiology, 50(8):1189-1198.

DOI: https://doi.org/10.1007/s00127-015-1040-3 


\section{Cross-sectional time trends in psychological and somatic health complaints among adolescents:}

a structural equation modelling analysis of 'Health Behaviour in School-aged Children' data from Switzerland

Authors and affiliations

Michelle Dey ${ }^{1}$, Anthony F Jorm ${ }^{1}$, Andrew J Mackinnon ${ }^{2}$

1 Centre for Mental Health, Melbourne School of Population and Global Health, University of Melbourne, 207 Bouverie Street, Melbourne, VIC 3010, Australia

2 Orygen, The National Centre of Excellence in Youth Mental Health, Centre for Youth Mental Health, University of Melbourne, 35 Popular Road, Parkville, VIC 3052, Australia

\section{Corresponding author:}

Michelle Dey

Centre for Mental Health

Melbourne School of Population and Global Health

University of Melbourne

207 Bouverie Street

Melbourne, VIC 3010, Australia

Email: michelle.dey@unimelb.edu.au

Telephone: +61390357620

Fax: +61 393476929 


\section{ABSTRACT}

Purpose: This study examined cross-sectional time trends in health complaints among adolescents living in Switzerland, including differences between population subgroups and sources of differential response to items.

Methods: Swiss data were analysed from the Health Behavior in School-aged Children (HBSC; including 11- to 15-years old) from 1994 ( $\mathrm{n}=7008), 1998(\mathrm{n}=8296), 2002(\mathrm{n}=9066)$ and 2006 $(n=9255)$. Structural equation modelling was used to assess 1) the structure of the HBSC Symptom Checklist (HBSC-SCL; questionnaire, which asks about the frequency of eight health complaints) and 2) associations between the HBSC-SCL with year of data collection and demographic characteristics of the participants.

Results: Two correlated factors fitted the data better than a single factor. The psychological factor included the items 'feeling low', 'irritability and bad temper', 'nervousness' and 'difficulties in getting to sleep', and the somatic factor the items 'headache', 'backache', 'stomach ache' and 'dizziness'. Relative to 1994, lower levels of psychological health complaints were experienced in 1998, 2002 and 2006. However, the changes were only minor. In contrast, somatic health complaints increased monotonically over the years of the survey. Experiencing psychological and somatic health complaints was more pronounced with age among females relative to males and was associated with living in particular language regions of Switzerland.

Conclusions: Different cross-sectional time trends were identified for the psychological and somatic latent variables, indicating that both factors should be investigated when studying period effects.

Key words: Health Behavior in School-aged Children (HBSC); health complaints; time trends; structural equation modelling; differential item functioning 


\section{INTRODUCTION}

Researchers have considered the question of whether rates of mental health problems (including externalizing and internalizing problems) in young people have increased over the years. Bor and colleagues [1] concluded in their review that no worsening in mental health problems has occurred in younger children (up to age 11). Furthermore, externalizing problems (e.g., hyperactivity or conduct problems) among adolescents did not change over time. In contrast, internalizing problems (e.g., symptoms of anxiety or depression) were shown to have increased among adolescent females (results for males were less consistent).

A study by Hagquist [2] that was included in the above-mentioned review analysed Swedish data from the Health Behaviour in School-aged Children (HBSC), a four-yearly international survey of 11to 15-year old adolescents [3,4]. More precisely, Hagquist [2] used a composite measure of four items (e.g., feeling low, being nervous) of the HBSC Symptom Checklist (HBSC-SCL). These items were labelled as psychological health complaints by other authors $[5,6]$ and can be interpreted as internalizing mental health problems. An increase in such internalizing psychological health complaints were found between $1985 / 1986$ and 2005/2006 among adolescents attending the $9^{\text {th }}$ grades from Sweden, particularly among girls [2].

Other publications have also reported cross-sectional time trends in the HBSC-SCL [7-11], but were not included in the review by Bor et al. [1]. Some of these contradict the above conclusions. For instance, analyses of Austrian data [7] showed a decrease in health complaints between 1994 and 2006. Even though this decrease was less pronounced among the oldest females in the sample (15years old), it nevertheless contradicts the worsening described for this particular socio-demographic subgroup in the above-mentioned review article [1] and in the Swedish HBSC study [2].

The inconsistencies in HBSC-studies from different countries may be partially attributable to differences in the methods of analysis used. For instance, some authors studied a scale that included all eight items of the HBSC-SCL [9,11], whereas others used scales that excluded some items [2,7]. 
Again others reported time trends in particular health complaints (i.e., in single items $[8,10])$. The dimensionality of the HBSC-SCL was not considered by all authors. Using a scale that includes all eight health complaints may be defensible if these items are indeed unidimensional, a structure that was proposed by some authors [12]. However, Haugland et al. [5] suggested that two correlated factors - a psychological factor (including the items 'feeling low'; 'irritability and bad temper'; 'nervousness'; 'difficulties in getting to sleep') and a somatic factor (including the items 'headache'; 'backache'; 'stomach ache'; 'dizziness') - represent a better fit (also see [6]).

The aim of the present study was to examine cross-sectional time trends in the HBSC-SCL by using HBSC data from Switzerland, which has not been subject to such analyses so far. Based on the abovementioned limitations of studies using the HBSC-SCL, analyses about the dimensionality of this instrument formed the basis for our investigation. More specifically, confirmatory factor analysis (CFA) was used to evaluate and compare two models - one with a single latent variable and one with two correlated latent factors (a psychological and a somatic). The second phase of the analysis studied changes over time in the latent variables identified by the CFA. Since it is possible that time effects occur on particular items, as well as on latent factors, we also examined direct effects of survey year on particular items of the HBSC-SCL. In other words, we aimed to test whether respondents at the same level on a latent variable had higher or lower levels of endorsing particular items belonging to this factor (see [13]). The possibility that the meaning of particular items of a measure have changed over time has not been, to the best of our knowledge, tested so far for the HBSC-SCL.

\section{METHODS}

\section{Procedure}

Data were used from the HBSC from Switzerland, which has participated in the WHO collaborative international survey since 1986 [3,4]. For the current study, cross-sectional data from survey years 1994 [14], 1998 [15], 2002 [16] and 2006 [17] were considered, because only these points of data collection included all items of the HBSC-SCL. Details about the survey procedure have been 
described elsewhere ([3,4]; also see http://www.hbsc.ch). In brief, classes from the $5^{\text {th }}$ to the $9^{\text {th }}$ grade served as primary sampling unit. All students (mostly between 11 and 15 years old) of a selected class could voluntarily decide to participate and the study was conducted in accordance to ethical standards. The questionnaires were available in three languages (German, French and Italian) and were filled out during class hours.

\section{Measures}

\section{HBSC Symptom Checklist}

Health complaints were measured with the HBSC Symptom Checklist (HBSC-SCL), which has demonstrated reliability and validity [18]. Participants were asked about the frequency with which they had experienced the following health complaints over the previous six months: 1) feeling low; 2) irritability or bad temper; 3) nervousness; 4) difficulties in getting to sleep; 5) headache; 6) backache; 7) stomach ache; 8) dizziness. A five-point response scale was used, including the categories 'rarely or never', 'about every month', 'about every week', 'more than once a week' and 'about every day'.

\section{Sociodemographic characteristics}

The following socio-demographic characteristics were used: 1) sex; 2) age; and 3) language region (German-, French- or Italian-speaking).

\section{Exclusion}

There were 46910 participants in the total data set, but 4078 (8.7\%) were excluded because they were younger or older than the targeted age group (11-15 years) or had missing data on age or sex. The HBSC-SCL was administered to only half of the participants in the 1994 survey. Hence, a further $7626(51 \%)$ of this survey year were excluded. Lastly, 1581 participants $(n=4.5 \%)$ with missing data in any of the HBSC-SCL items were excluded. Hence, the final analytical sample consisted of 33625 participants. 


\section{Statistical analyses}

Socio-demographic characteristics between survey years were compared using chi-square analysis. Structural Equation Modelling (SEM) was conducted with AMOS v22 [19]. In a first step, confirmatory factor analysis (CFA) models were fitted to the data of the entire sample (i.e., across survey years). Based on the literature, two models were tested: a model with a single factor (i.e., all items of the HBSC-SCL were assumed to be represented by the same factor; [12]) was compared to a model comprising two correlated factors (psychological and somatic) derived from previous research $[5,6]$.

In a second step, a multiple indicators, multiple causes (MIMIC) model was built on the results of the CFA. This method was adapted from the model presented by Christensen et al. [13]. It included survey year, age, sex and language region as predictors of the latent variables. Each of these covariates was measured by a single indicator or set of dummy variables. Hence, the associations between the covariates and latent variable(s) can be interpreted as comparable to a multiple regression analysis. Because previous studies showed increasing sex differences with age in regard to health complaints $[5,6,11,20,21]$, we also included an interaction term of age by sex in the model. In addition to the effects of the covariates and the interaction term on the latent variable(s), direct effects of these predictors and the interaction term on each HBSC-SCL item were assessed. A significant coefficient for such a path indicates differential item functioning (DIF). If, for example, participants from more recent survey years showed higher levels of endorsement of the item 'irritability or bad temper' than participants from earlier years with the same level on the health complaint factors, the coefficient of this direct path would be significant.

Maximum likelihood estimation was used for all analyses. The results of the chi-square test were reported $\left(\mathrm{H}_{0}=\right.$ model is correct [22]). Because this test often reveals significant results when the sample is large (as in our case), the following goodness-of-fit indices are reported as well: 1) Comparative Fit Index (CFI; [23]); 2) Tucker-Lewis Index (TLI; [24]); and 3) the root mean square error of approximation (RMSEA; [25]). Values of the CFI and TLI >.95 are indicative for a well- 
fitting model. Regarding the RMSEA, values $\leq .05$ indicate a good fit [25]. Additional to the RMSEA, AMOS provides a closeness of fit indicator (PCLOSE), which tests the hypothesis that RMSEA $<.05$ in the population. Values $>.50$ indicate a good fit [26]. Confidence intervals were obtained by bootstrapping using 5000 resamplings from the original sample.

\section{RESULTS}

Socio-demographic characteristics of the sample are presented in Table 1.

\section{Confirmatory factor analysis}

The model with one factor (i.e., all eight items of the HBSC-SCL load on a single latent variable) indicated an inadequate fit $\left(\chi^{2}=5519.834, \mathrm{df}=20, \mathrm{p}<.001 ; \mathrm{CFI}=.907 ; \mathrm{TLI}=.870 ; \mathrm{RMSEA}=.090\right.$ (90\% CI: .088 -.092), PCLOSE < .001). To improve fit, residuals of two pairs of items were permitted to correlate, namely 'headache' with 'stomach ache', as well as 'irritability or bad temper' with 'feeling low'. The corresponding model fit statistics were better than in the initial model $\left(\chi^{2}=\right.$ 2817.881, $\mathrm{df}=18, \mathrm{p}<.001 ; \mathrm{CFI}=.953 ; \mathrm{TLI}=.926 ;$ RMSEA $=.068$ (90\% CI: .066 -.070), PCLOSE $<.001)$. However, the adapted one-factor model was still inferior when compared to the model with two correlated factors (see Figure 1$)\left(\chi^{2}=1431.492, \mathrm{df}=19, \mathrm{p}<.001 ; \mathrm{CFI}=.976 ;\right.$ TLI = .965; RMSEA $=.047(90 \%$ CI: .045 -.049), PCLOSE $=.991)$. Therefore, the two-factor model formed the basis of the MIMIC model.

\section{MIMIC model}

The MIMIC model is shown in Figure 2. Paths from each covariate (survey year, age, sex, age by sex, and language region) were drawn to both latent variables (i.e., to the psychological and to the somatic factor). Paths from each covariate (including the interaction term) to each item of the HBSC-SCL 
were included. This configuration makes it possible to test whether the effects of a particular covariate on each of the items cannot be accounted for by the effect of the covariate on the latent variable.

Because the direct paths from the covariates to the items are measuring a differential effect, at least one path for each factor must be constrained to zero so that it can be used as a reference against which the effect of each covariate on the other items is evaluated. For the current analyses, the direct paths to the item 'feeling low' (belonging to the psychological factor) and the direct paths to the item 'headache' (belonging to the somatic factor) were constrained. In preliminary analyses, age was represented by a set of four dummy variables (11 vs. 12, 13, 14, and 15). However, since the effects of age were primarily linear, age was treated as a continuous variable in the final model. The significance of the interaction of age and sex was evaluated by adding the paths to the model containing these variables but without their interaction. Both models including only paths to the latent variables, and to the latent variables and each item provided a significant improvement in model fit (changes in chi-square from the model with no interaction paths were $\chi^{2}=233.808, \mathrm{df}=2, \mathrm{p}<.001$ and $\chi^{2}=325.687, \mathrm{df}=8, \mathrm{p}<.001$ respectively). Accordingly, these paths were retained in the final model yield fit statistics as follows: $\chi^{2}=1376.097, \mathrm{df}=19, \mathrm{p}<.001 ; \mathrm{CFI}=.994 ; \mathrm{TLI}=.965 ; \mathrm{RMSEA}=.046$ (90\% CI: .044-.048), PCLOSE $=.999$.

\section{Covariates and latent factors}

Standardized path coefficients and 95\% bootstrap confidence intervals are shown in Table 2. Psychological health complaints were at lower levels in 1998, 2002 and 2006 relative to 1994. However, psychological health complaints did not decrease linearly over the years, as shown by the individual parameter estimates (1998: -.073; 2002: -.091; 2006: -.045). Somatic health complaints increased over the years, as indicated by increasing estimates (1998: .037; 2002: .097; 2006: .127). The interactions of age and sex were significant in regard to the two latent variables. In order to simplify interpretations of these terms, they were reparameterized to yield separate estimates of the effect of age in males and for females. These coefficients indicate that the increase in the levels of 
psychological and somatic health complaints with age were more pronounced among females compared to those for males. Greater levels of psychological and somatic health complaints were found in Italian- vs. German-speaking language regions. Furthermore, psychological health complaints were additionally associated with living in a French-speaking language region.

\section{Differential Item Functioning - direct effects of covariates on individual items}

Greater endorsement in more recent survey years relative to 1994 was found for 'irritability' (1998, 2002, 2006) and 'nervousness' (1998). Endorsing 'difficulties in getting to sleep' was lower in 1998 (-.035) compared to 1994, but greater in $2002(.070)$ and 2006 (.085). Survey year was negatively associated with the items 'backache' (1998 vs. 1994; 2002 vs. 1994) and 'stomach ache' (1998 vs. 1994; 2002 vs. 1994; 2006 vs. 1994). The interactions of age and sex were significant for all items, except for 'stomach ache'. Greater endorsement of the item 'irritability or bad temper' with age was found for males, whereas female age did not have a direct effect on this item. The negative association between age and 'nervousness' was only significant for females. Furthermore, the direct negative effect of age on 'difficulties in getting to sleep' was larger for females relative to males. A stronger positive association with age was found for males in regard to the item 'backache', but for females in regard to 'dizziness'. Participants living in French-speaking regions showed, relative to those from German-speaking parts, a greater endorsement of the items 'difficulties in getting to sleep', 'backache' and 'stomach ache', but lower levels of endorsement for 'dizziness'. Direct negative effects of Italian-speaking language region were found for 'irritability or bad temper', 'difficulties in getting to sleep', 'backache' and 'dizziness'. In contrast, Italian-speaking participants showed greater endorsement of the item 'nervousness'.

\section{Scale scores}

Sum scores of the four psychological items and the four somatic items were calculated. Means and standard deviations (SD) of these scores are presented in Table 3 by survey year and socio- 
demographic variables. As indicated by the simple linear regression analyses, the scores of the psychological items were significantly lower in 1998 and 2002 relative to 1994. Regarding the somatic score, higher scores were found in 2002 and 2006 relative to 1994. Among males, age was only significantly associated with the somatic score, with higher scores in 13-, 14- and 15- relative to 11-year olds. Among females, age was significantly associated with the psychological and somatic scores, with continuously increasing values between 11 and 14 . Females who were 15 years old also had significantly higher scores relative to 11-years old, but did not differ to a large extent from 14years old females (see Table 3). French-speaking participants had higher scores in both scales factors compared to German-speaking participants. Italian-speaking adolescents were more likely to have higher scores in the psychological, but lower scores in the somatic scale.

\section{DISCUSSION}

SEM was used to explore the dimensionality of the HBSC-SCL. As suggested by others [5,6], a model with two correlated factors - a psychological and a somatic - was a good fit, while a model with only one factor did not adequately represent the data.

\section{Effects of predictors on latent factors}

Time trends in the psychological factor

The psychological factor in our study consisted of items that are primarily indicative of internalizing mental health problems, namely 'feeling low', 'irritability and bad temper', 'nervousness' and 'difficulties in getting to sleep'. Fewer of these psychological problems were experienced in 1998, 2002 and 2006 relative to 1994 . However, the sizes of the path coefficients were small (<.10), indicating that changes over time were only minor. Comparable results were also found in the linear regression analyses, where the sum score of all psychological items was used as the outcome.

Hagquist used an identical sum score, but concluded that psychological health complaints increased 
among older adolescents in Sweden between 1985/1986 and 2005/2006, particularly among girls [2]. Even though we did not identify such an increase in the present study, time trends in psychological health complaints should be thoroughly monitored in coming years in Switzerland because such complaints seemed to have increased slightly between 2002 and 2006.

Time trends in the somatic factor

The somatic factor included four items, namely 'headache', 'backache', 'stomach ache' and 'dizziness'. This dimension of health complaints seem to have increased slightly but consistently over the years in our samples, as indicated by the SEM analyses. This trend was also observable in the linear regression analyses, where a sum score of the four somatic items was used as the outcome.

Regarding our study, it must be emphasized that the term 'somatic' was used to describe the second factor of our model in accordance with the label used by other researchers $[5,6]$. However, the symptoms that load on this latent variable may also be indicative of the presence of a mental health problem, such as anxiety or depression (e.g., $[27,28])$, a possibility that is also supported by the substantial correlation between the somatic and psychological factors. The term '(psycho)somatic' might be better suited to describe the nature of this second latent variable. Hence, even though the 'psychological factor' did not increase over time in our study, it cannot be ruled out that psychological distress—-manifest as psychosomatic symptoms—has increased among adolescents living in Switzerland.

That only the somatic factor increased over time may have been due to a decreasing pressure to react in a stoic and controlled manner (see [29]) to (psycho)somatic, but not to more purely psychological health complaints, such as feeling low. However, this hypothesis is contradicted by evidence that difficulties in talking with others about worries and mental health problems (including more purely psychological symptoms) have decreased over time in Switzerland (unpublished data). 
Another possible explanation for higher levels of somatic health complaints in more recent years is that more time is spent using computers (e.g., on social media and online chatting; [30]). Such screenbased activities have been shown to be associated with backache and headache among adolescents [31].

\section{Other predictors}

Confirming earlier studies [5-7,9-11,20,21], females had higher psychological and somatic scores than males in each age group (see Table 3). Various explanations for these gender differences have been proposed. The qualitative study of MacLean et al. [29], for instance, indicated that both males and females are expected to deal with psychological and somatic symptoms "in stoic, controlled and independent ways". However, this expectation seems to act as a 'rule' for males, for which deviations (e.g., showing psychological symptoms publicly) are likely to be perceived as signifying weakness and, hence, as unacceptable. In contrast, being stoic, controlled and independent seem only to act as 'guidelines' for females, who therefore may more easily decide not to conform. Furthermore, pubertal changes might have an especially negative effect on females [32].

Our finding that older age in males and females was associated with both latent variables also confirms earlier studies [5-7,9,20,21,33], and might, among other things, be explained by a growing self-awareness among older adolescents, which might increase the perception and reporting of health complaints (see [6]) or by increasing school-related stress, which seems to be associated with health complaints [34].

Our MIMIC model showed a significant interaction between sex and age: the increases in psychological and somatic health complaints with age were more pronounced among females compared to males, which confirms earlier findings $[5,6,11,20,21]$.

We also demonstrated that experiencing health complaints differs between language regions: relative to German-speaking participants, adolescents from Italian-speaking regions were more likely to report 
psychological and somatic health complaints. Furthermore, French-speaking participants experienced more psychological health complaints than German-speaking people. Similar differences between language regions were also observed in other studies and are possibly at least partly attributable to cultural differences in response styles [35].

\section{Direct effects of year of data collection and socio-demographic variables on latent factors}

$D I F$ was found in regard to various predictors. The magnitude of this item bias was $<.10$ for the predictors survey year and language region. The only item that showed a relatively distinct pattern as a function of survey year was 'sleeping difficulties', whose endorsement increased consistently between 1998 and 2006 (in line with [10]). Except for the item about dizziness, we believe that DIF as a function of language region is not attributable to linguistic differences. Both French- and Italianspeaking participants were less likely to endorse this item relative to German-speaking adolescents. In the German version, this health complaint was described with easily understood terms ("Ich fühlte mich schwindlig”; translated in English: "I felt dizzy”). In contrast, the French- and Italian-speaking versions initially used the term 'vertigo' (French: “j'avais des vertiges “; Italian: "ho sofferto di vertigini“), possibly leading to lower endorsement by adolescents because this expression describes a relative strong feeling (French) or because it is more often used to describe "afraid of heights" and may have a more medical and less easily understood character (Italian). A simpler description of feeling dizzy, or a term that describes a less strong feeling, was only provided in brackets in the French and Italian version.

Higher DIF (>.10) were found for paths involving age and sex, for instance in regard to the item 'irritability or bad temper'. The path coefficients presented in Table 2 indicate that males with the same level of psychological health complaints show a greater endorsement of this item with age relative to the reference item 'feeling low'. In contrast, no direct effect of female age was found on this item. It is possible that this particular health complaint becomes a more essential part of the 
psychological factor among males with increasing age (relative to feeling low), whereas 'feeling low' remains a core component of the psychological factor among females.

\section{Limitations}

Despite several strengths of the present study (e.g., comparable methods over time and large sample sizes), the following limitations must be considered. Firstly, DIF was found in regard to several predictors. Secondly, the path coefficients from the predictors to the latent variables were rather small, possibly due to the use of a population-based rather than clinical sample. Thirdly, pupils who were absent on the day of data collection were not represented. This might have introduced a bias, because adolescents with health complaints are more likely to be absent from school [27]. Fourthly, we did not correct for the clustering effect of schools in the statistical analyses. However, as shown by others [10], this effect was presumably only weak and did not change the findings to a large extent. Fifthly, using various cross-sectional surveys allows for analysing cross-sectional time trends, but not for drawing a causal conclusion. Sixthly, the HBSC-SCL mainly consists of internalizing mental health symptoms. Hence, no points about period effects in externalizing symptoms can be made. Lastly, we did not include other covariates in the MIMIC model that might have been related to psychological and somatic health complaints, such as socio-economic status (see for instance [33]), because no reliable or valid measure of this variable was available for all survey years.

\section{CONCLUSION}

The results of the present study suggest that cross-sectional time trends for the psychological and somatic health complaints in a large sample of Swiss adolsents follow differing trajectories. Hence, it is important to disaggregate these factors when studying temporal effects rather than rely on an single score as outcome (i.e., one which includes all HBSC-SCL items). Potential explanations for the observed increase in the somatic factor (e.g., increase in on-screen activities) have been raised in the present article, but need to be investigated specifically in subsequent studies. Finding factors that 
contribute to an increase in somatic, but not psychological health complaints, is a challenge, but future research should address possible predictors such as physical activity, school and family environment. Since no single predictor is likely to be able to explain the identified time trends, multiple variables and their interaction should also be considered. DIF was found for several predictors. Reasons need to be investigated in more detail in future studies and care may need to be exercised when comparing raw scale scores from different periods of time and from different socio-demographic sub-groups.

Acknowledgements: The authors wish to acknowledge all the people who were responsible for the HBSC surveys conducted in Switzerland: Yann Le Gauffey in 1994 [14], Béatrice Janin Jacquat in 1998 [15], Holger Schmid in 2002 and 2006 [16,17] and Marina Delgrande Jordan in 2006 [17]. We would also like to thank Charlotte Eidenbenz, Natalia Estévez and Ivan Lamorte for their valuable evaluation regarding language differences in items of the HBSC-SCL and Stefan Cvetkovski for his methodological input. Michelle Dey is supported by a fellowship (P2ZHP1_148710) from the Swiss National Science Foundation.

Conflict of interest: The authors declare that they have no conflicts of interest. 


\section{References}

1. Bor W, Dean A, Najman J, Hayatbakhsh R (2014) Are child and adolescent mental health problems increasing in the 21st century? A systematic review. Aust N Z J Psychiatry 48 (7):606-616

2. Hagquist C (2010) Discrepant trends in mental health complaints among younger and older adolescents in Sweden: an analysis of WHO data 1985-2005. J Adolesc Health 46 (3):258-264. doi:10.1016/j.jadohealth.2009.07.003

3. Currie C, Nic Gabhainn S, Godeau E (2009) The Health Behaviour in School-aged Children: WHO collaborative cross-national (HBSC) study: origins, concept, history and development 1982-2008. Int J Public Health 54 Suppl 2:131-139. doi:10.1007/s00038-009-5404-x

4. Roberts C, Freeman J, Samdal O, Schnohr CW, de Looze ME, Gabhainn SN, Iannotti R, Rasmussen M, Grp IHS (2009) The Health Behaviour in School-aged Children (HBSC) study: methodological developments and current tensions. Int J Public Health 54:140-150. doi:10.1007/S00038-009-5405-9

5. Haugland S, Wold B, Stevenson J, Aaroe LE, Woynarowska B (2001) Subjective health complaints in adolescence - a cross-national comparison of prevalence and dimensionality. E J Public Health 11 (1):4-10. doi:10.1093/eurpub/11.1.4

6. Hetland J, Torsheim T, Aaro LE (2002) Subjective health complaints in adolescence: dimensional structure and variation across gender and age. Scand J Public Health 30 (3):223-230. doi:10.1080/140349402320290953

7. Dür W, Griebler R, Flaschberger E, Felder-Puig R (2011) Gesundheitliche Beschwerden österreichischer Jugendlicher - Ergebnisse der HBSC-Studie 1994 bis 2006. Wien Med Wochenschr 161 (7-8):174-149. doi:10.1007/s10354-010-0854-6.

8. Holstein B, Andersen A, Due P, Hansen EH (2009) [Children's and adolescent's use of medicine for aches and psychological problems: secular trends from 1988 to 2006]. Ugeskr Laeger 171 (1-2):24-28 9. Ottova V, Hillebrandt D, Ravens-Sieberer U, Deutschland H-T (2012) Trends in subjective health and well-being of children and adolescents in Germany: results of the Health Behaviour in Schoolaged Children (HBSC) study 2002 to 2010. Gesundheitswesen 74:S15-S24. doi:10.1055/S-00321312640 
10. Pallesen S, Hetland J, Sivertsen B, Samdal O, Torsheim T, Nordhus IH (2008) Time trends in sleep-onset difficulties among Norwegian adolescents: 1983-2005. Scand J Public Health 36 (8):889895. doi:10.1177/1403494808095953

11. Levin KA, Currie C, Muldoon J (2009) Mental well-being and subjective health of 11- to 15-yearold boys and girls in Scotland, 1994-2006. Eur J Public Health 19 (6):605-610.

doi:10.1093/Eurpub/Ckp046

12. Ravens-Sieberer U, Erhart M, Torsheim T, Hetland J, Freeman J, Danielson M, Thomas C (2008) An international scoring system for self-reported health complaints in adolescents. Eur J Public Health 18 (3):294-299. doi:10.1093/eurpub/ckn001

13. Christensen H, Jorm AF, Mackinnon AJ, Korten AE, Jacomb PA, Henderson AS, Rodgers B (1999) Age differences in depression and anxiety symptoms: a structural equation modelling analysis of data from a general population sample. Psychol Med 29 (2):325-339

14. Le Gauffey Y (1994) Das Gesundheitsverhalten Schweizer Schüler. Distributed by FORS, Lausanne, 2002. Schweizerische Fachstelle für Alkohol-und andere Drogenprobleme-SFA, Case postale 870,1001 Lausanne

15. Janin Jacquat B (1998) Das Gesundheitsverhalten Schweizer Schüler. Distributed by FORS, Lausanne, 2002. Schweizerische Fachstelle für Alkohol-und andere Drogenprobleme-SFA, Case postale 870,1001 Lausanne

16. Schmid H (2002) Das Gesundheitsverhalten Schweizer Schüler. Distributed by FORS, Lausanne, 2002. Schweizerische Fachstelle für Alkohol-und andere Drogenprobleme-SFA, Case postale 870, 1001 Lausanne

17. Schmid H, Delgrande Jordan M (2006) Das Gesundheitsverhalten Schweizer Schüler. Distributed by FORS, Lausanne, 2002. Schweizerische Fachstelle für Alkohol-und andere Drogenprobleme-SFA, Case postale 870, 1001 Lausanne

18. Haugland S, Wold B (2001) Subjective health complaints in adolescence-reliability and validity of survey methods. J Adolesc 24 (5):611-624. doi:10.1006/jado.2000.0393

19. Arbuckle JL (2013) Amos (Version 22). SPSS, Chicago 
20. Cavallo F, Zambon A, Borraccino A, Raven-Sieberer U, Torsheim T, Lemma P (2006) Girls growing through adolescence have a higher risk of poor health. Qual Life Res 15 (10):1577-1585. doi:10.1007/s11136-006-0037-5

21. Torsheim T, Ravens-Sieberer U, Hetland J, Valimaa R, Danielson M, Overpeck M (2006) Crossnational variation of gender differences in adolescent subjective health in Europe and North America. Soc Sci Med 62 (4):815-827. doi:10.1016/j.socscimed.2005.06.047

22. Blunch NJ (2011) Introduction to structural equation modelling using SPSS and AMOS. SAGE Publications Ltd, London

23. Bentler PM (1990) Comparative Fit Indexes in Structural Models. Psychol Bull 107 (2):238-246. doi:10.1037/0033-2909.107.2.238

24. Tucker LR, Lewis C (1973) A reliability coefficient for maximum likelihood factor analysis. Psychometrika 38:1-10

25. Brown MW, Cudeck R (1992) Alternative ways of assessing model fit. Sociol Methods Res 21:230-258

26. Jöreskog KG, Sörbom D (1996) LISREL 8: User’s reference guide. Chicago

27. Bellini B, Arruda M, Cescut A, Saulle C, Persico A, Carotenuto M, Gatta M, Nacinovich R, Piazza FP, Termine C, Tozzi E, Lucchese F, Guidetti V (2013) Headache and comorbidity in children and adolescents. J Headache Pain 14:79. doi:10.1186/1129-2377-14-79

28. Campo JV (2012) Annual research review: functional somatic symptoms and associated anxiety and depression - developmental psychopathology in pediatric practice. J Child Psychol Psychiatry 53 (5):575-592. doi:10.1111/j.1469-7610.2012.02535.x

29. MacLean A, Sweeting H, Hunt K (2010) 'Rules' for boys, 'guidelines' for girls: gender differences in symptom reporting during childhood and adolescence. Soc Sci Med 70 (4):597-604.

doi:10.1016/j.socscimed.2009.10.042

30. Nelson MC, Neumark-Sztainer D, Hannan PJ, Sirard JR, Story M (2006) Longitudinal and secular trends in physical activity and sedentary behavior during adolescence. Pediatrics 118 (6):E1627-

E1634. doi:10.1542/peds.2006-0926 
31. Torsheim T, Eriksson L, Schnohr CW, Hansen F, Bjarnason T, Valimaa R (2010) Screen-based activities and physical complaints among adolescents from the Nordic countries. BMC Public Health 10. doi:10.1186/1471-2458-10-324

32. Benjet CB, Hernandez-Guzman L (2002) A short-term longitudinal study of pubertal change, gender, and psychological well-being of Mexican early adolescents. J Youth Adolesc 31 (6) 33. Holstein BE, Currie C, Boyce W, Damsgaard MT, Gobina I, Kokonyei G, Hetland J, de Looze M, Richter M, Due P, Grp HSIF (2009) Socio-economic inequality in multiple health complaints among adolescents: international comparative study in 37 countries. Int J Public Health 54:260-270. doi:10.1007/s00038-009-5418-4

34. Torsheim T, Wold B (2001) School-related stress, school support, and somatic complaints: a general population study. J Adolescent Res 16 (3):293-303. doi:10.1177/0743558401163003 35. Dey M, Gmel G, Mohler-Kuo M (2013) Body mass index and health-related quality of life among young Swiss men. BMC Public Health 13:1028. doi:10.1186/1471-2458-13-1028 
Table 1: Socio-demographic characteristics by survey year for the HBSC

\begin{tabular}{|c|c|c|c|c|c|c|c|}
\hline & \multirow[t]{2}{*}{ Survey year: } & TOTAL & 1994 & 1998 & 2002 & 2006 & \multirow{3}{*}{$\mathrm{p}$} \\
\hline & & n (\%) & $\mathrm{n}(\%)$ & $\mathrm{n}(\%)$ & $\mathrm{n}(\%)$ & $\mathrm{n}(\%)$ & \\
\hline & TOTAL & 33625 (100) & $7008(100)$ & $8296(100)$ & $9066(100)$ & $9255(100)$ & \\
\hline \multicolumn{8}{|c|}{ Language region } \\
\hline German & & $23019(68.5)$ & $4093(58.4)$ & $5906(71.2)$ & $6549(72.2)$ & 6471 (69.9) & \multirow[t]{3}{*}{$<.001$} \\
\hline French & & 8266 (24.6) & $2150(30.7)$ & $1906(23.0)$ & 1981 (21.9) & $2229(24.1)$ & \\
\hline Italian & & $2340(7.0)$ & 765 (10.9) & $484(5.8)$ & $536(5.9)$ & $555(6.0)$ & \\
\hline \multicolumn{8}{|l|}{ Age } \\
\hline 11 & & 5444 (16.2) & 884 (12.6) & 1409 (17.0) & $1488(16.4)$ & $1663(18.0)$ & \multirow[t]{5}{*}{$<.001$} \\
\hline 12 & & $6758(20.1)$ & $1387(19.8)$ & $1698(20.5)$ & 1685 (18.6) & $1988(21.5)$ & \\
\hline 13 & & 7501 (22.3) & $1561(22.3)$ & 1789 (21.6) & $2138(23.6)$ & 2013 (21.8) & \\
\hline 14 & & 7308 (21.7) & $1649(23.5)$ & 1747 (21.1) & $1938(21.4)$ & 1974 (21.3) & \\
\hline 15 & & 6614 (19.7) & $1527(21.8)$ & 1653 (19.9) & $1817(20.0)$ & 1617 (17.5) & \\
\hline \multicolumn{8}{|l|}{$\operatorname{Sex}$} \\
\hline males & & $16541(49.2)$ & $3323(47.4)$ & $4169(50.3)$ & $4444(49.0)$ & 4605 (49.8) & \multirow[t]{2}{*}{.003} \\
\hline females & & $17084(50.8)$ & $3685(52.6)$ & 4127 (49.7) & $4622(51.0)$ & $4650(50.2)$ & \\
\hline
\end{tabular}

Note: $\mathrm{HBSC}=$ Health Behaviour in School-aged Children 
Figure 1: Confirmatory factor model for the 8-item HBSC Symptom Checklist

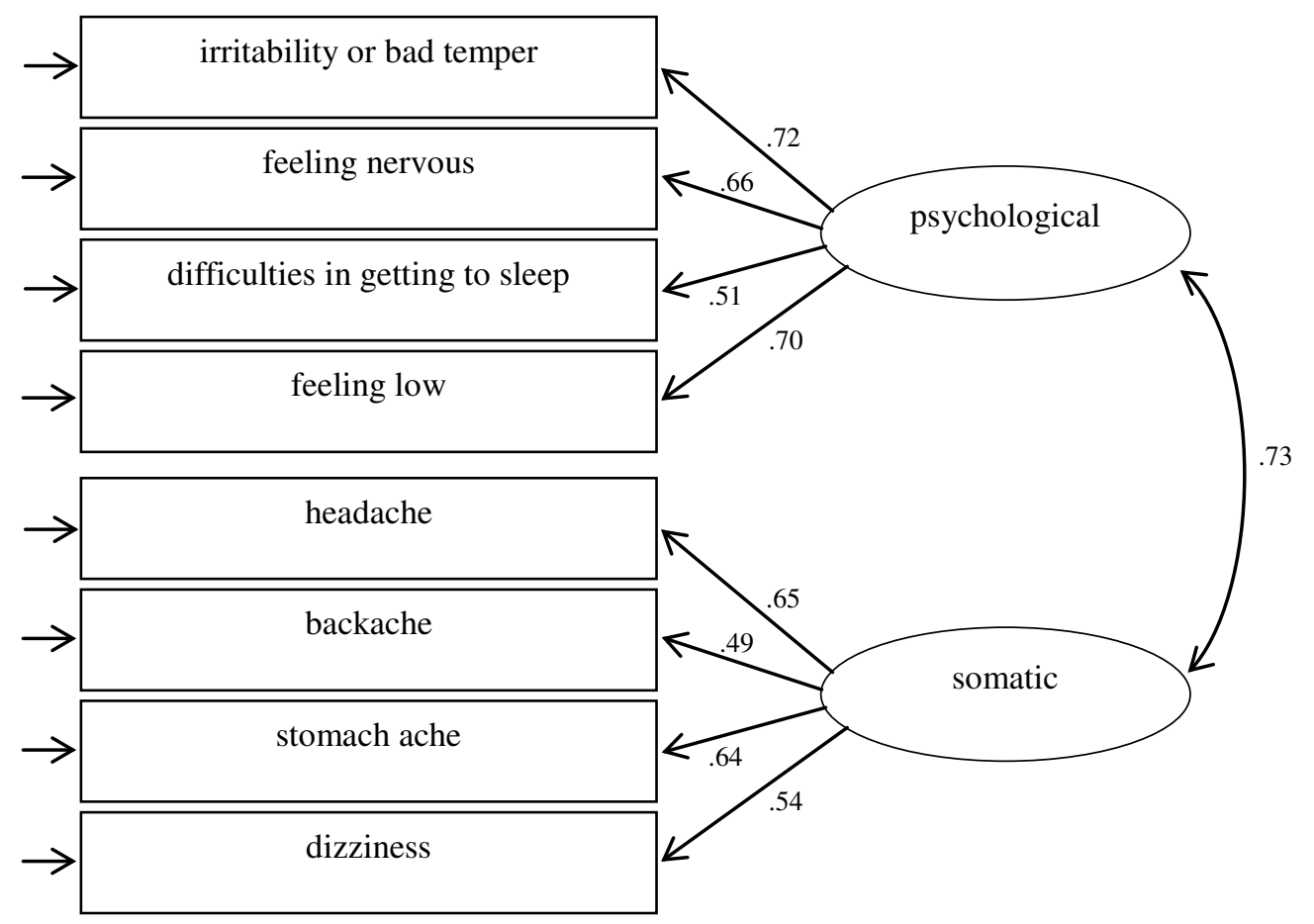

Note: Standardized coefficients are shown for the model fitted to the total sample (across survey years). All coefficients are statistically significant. 
Figure 2: Schematic illustration of the MIMIC model

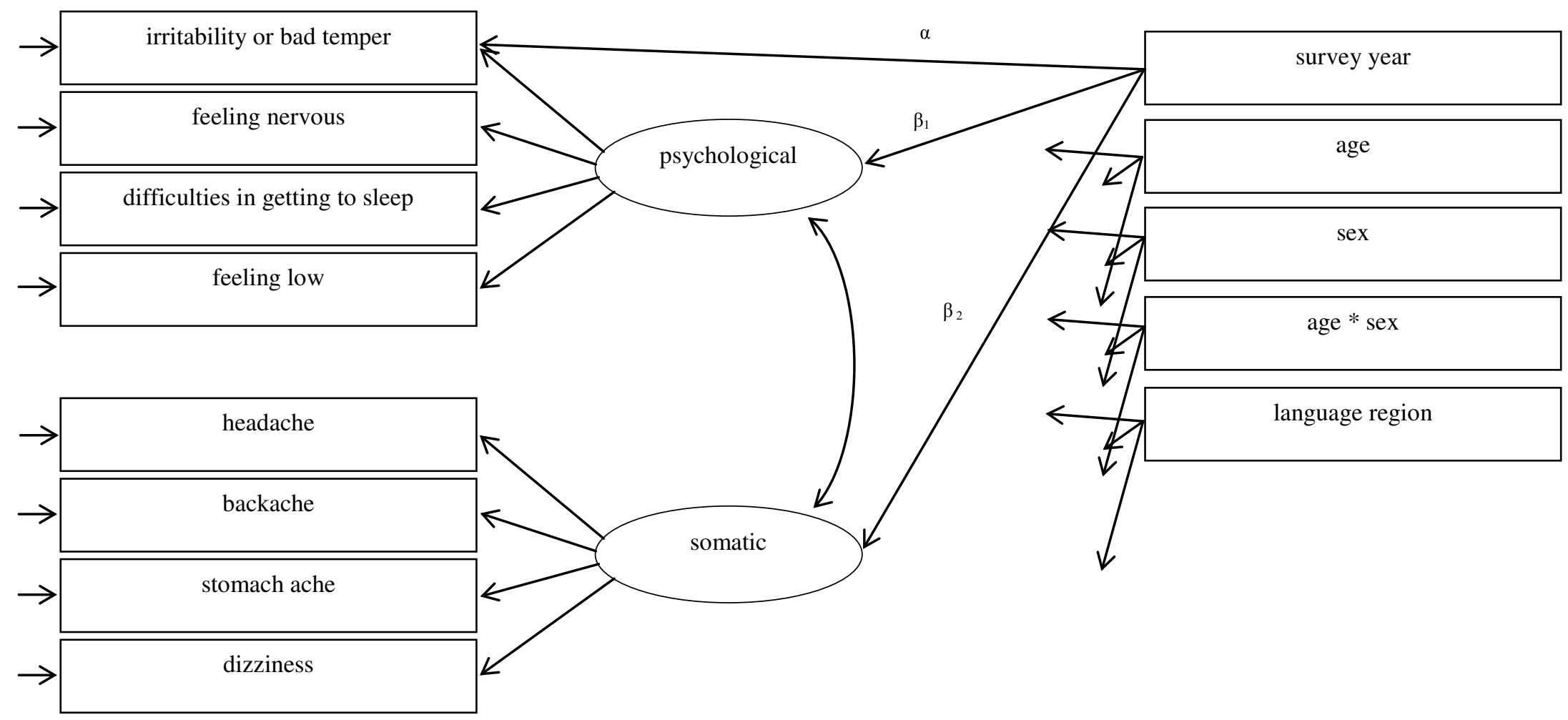

Note: All covariates (survey year, age, sex, language region) as well as the interaction term (age * sex) have paths to the 'psychological' and 'somatic' factors. For simplicity, this is shown only for the covariate 'survey year' (see paths $\beta_{1}$ and $\beta_{2}$ ). In addition, every covariate and the interaction term have a path to each of the eight items, with an example shown for the path from survey year to the item 'irritability or bad temper' $(\alpha)$. For simplicity, the free covariation between all predictors is not shown. 
Table 2: Standardized path coefficients (95\% bootstrap confidence intervals) for covariates on HBSC Symptom Checklist factors and items

\begin{tabular}{|c|c|c|c|c|c|c|}
\hline Survey year: & Survey year: & Survey year: & Age males & Age females & Language region: & Language region: \\
\hline 1998 vs. $1994^{1}$ & 2002 vs. $1994^{1}$ & 2006 vs. $1994^{1}$ & & & French vs. German ${ }^{1}$ & Italian vs. German $^{1}$ \\
\hline
\end{tabular}

Latent factor / items

\begin{tabular}{|c|c|c|c|c|c|c|c|}
\hline Psychological factor & $-.073(-.091,-.055)$ & $-.091(-.110,-.073)$ & $-.045(-.064,-.026)$ & $.326(.256, .399)$ & $.674(.602, .747)$ & $.080(.065, .095)$ & $.061(.045, .077)$ \\
\hline Feeling low ${ }^{1}$ & - & - & - & - & - & - & - \\
\hline $\begin{array}{l}\text { Irritability or bad } \\
\text { temper }\end{array}$ & $.069(.054, .082)$ & $.047(.033, .061)$ & $.068(.055, .082)$ & $.121(.067, .174)$ & $-.036(-.091, .017)$ & $.004(-.008, .016)$ & $-.043(-.054,-.032)$ \\
\hline Nervousness & $.039(.024, .055)$ & $.001(-.014, .015)$ & $.010(-.005, .025)$ & $.052(-.005, .105)$ & $-.132(-.190,-.076)$ & $.005(-.007, .017)$ & $.038(.026, .049)$ \\
\hline $\begin{array}{l}\text { Difficulties in getting } \\
\text { to sleep }\end{array}$ & $-.035(-.049,-.020)$ & $.070(.055, .084)$ & $.085(.070, .100)$ & $-.316(-.371,-.263)$ & $-.387(-.443,-.333)$ & $.050(.038, .061)$ & $-.012(-.024, .000)$ \\
\hline Somatic factor & $.037(.016, .057)$ & $.097(.076, .118)$ & $.127(.106, .147)$ & $.163(.080, .242)$ & $.419(.335, .497)$ & $-.006(-.022, .011)$ & $.037(.020, .055)$ \\
\hline Headache $^{1}$ & - & - & - & - & - & - & - \\
\hline Backache & $-.026(-.041,-.012)$ & $-.025(-.040,-.011)$ & $.003(-.012, .017)$ & $.631(.557, .686)$ & $.578(.524, .634)$ & $.061(.049, .072)$ & $-.019(-.031,-.008)$ \\
\hline Stomach ache & $-.027(-.042,-.013)$ & $-.040(-.055,-.025)$ & $-.018(-.033,-.004)$ & $-.124(-.178,-.071)$ & $-.037(-.090, .017)$ & $.067(.056, .079)$ & $-.007(-.019, .004)$ \\
\hline Dizziness & $.010(-.005, .023)$ & $-.013(-.028, .001)$ & $-.011(-.026, .004)$ & $.239(.184, .295)$ & $.244(.187, .300)$ & $-.053(-.064,-.042)$ & $-.084(-.096,-.073)$ \\
\hline
\end{tabular}


Table 3: Means and standard deviations of the psychological and somatic latent variable of the HBSC Symptom Checklist by survey year, male age, female age and language region as well as simple linear regression analyses on the psychological and somatic factors

\begin{tabular}{|c|c|c|c|c|}
\hline & \multicolumn{2}{|c|}{ Psychological sum score ${ }^{\mathrm{a}, \mathrm{c}}$} & \multicolumn{2}{|c|}{ Somatic sum score $^{\mathrm{b}, \mathrm{c}}$} \\
\hline & \multicolumn{3}{|c|}{ Standardized $\beta$ (linear } & \multirow{2}{*}{$\begin{array}{c}\text { Standardized } \beta \text { (linear } \\
\text { regression) }\end{array}$} \\
\hline & Mean (SD) & regression) & Mean (SD) & \\
\hline \multicolumn{5}{|l|}{ Survey year } \\
\hline $1994(n=7008)$ & $5.28(3.45)$ & reference & $2.82(2.68)$ & reference \\
\hline $1998(n=8296)$ & $4.76(3.41)$ & $-.063 * * *$ & $2.85(2.78)$ & .003 \\
\hline $2002(\mathrm{n}=9066)$ & $4.80(3.48)$ & $-.060 * * *$ & $3.11(2.91)$ & $.044 * * *$ \\
\hline $2006(n=9255)$ & $5.24(3.67)$ & -.005 & $3.36(3.12)$ & $.082 * * *$ \\
\hline \multicolumn{5}{|l|}{ Age males } \\
\hline $11(\mathrm{n}=2654)$ & $4.40(3.46)$ & reference & $2.26(2.59)$ & reference \\
\hline $12(\mathrm{n}=3410)$ & $4.44(3.35)$ & .004 & $2.35(2.56)$ & .014 \\
\hline $13(\mathrm{n}=3619)$ & $4.43(3.26)$ & .004 & $2.42(2.51)$ & $.025 *$ \\
\hline $14(\mathrm{n}=3527)$ & $4.43(3.23)$ & .003 & $2.55(2.64)$ & $.045 * * *$ \\
\hline $15(\mathrm{n}=3331)$ & $4.29(3.10)$ & -.013 & $2.49(2.54)$ & $.036^{* * *}$ \\
\hline \multicolumn{5}{|l|}{ Age females } \\
\hline $11(\mathrm{n}=2790)$ & $4.80(3.67)$ & reference & $2.87(2.88)$ & reference \\
\hline $12(\mathrm{n}=3348)$ & $5.23(3.58)$ & $.047 * * *$ & $3.26(2.94)$ & $.051 * * *$ \\
\hline $13(n=3882)$ & $5.71(3.58)$ & $.105 * * *$ & $3.65(3.03)$ & $.107 * * *$ \\
\hline $14(\mathrm{n}=3781)$ & $6.11(3.67)$ & $.149 * * *$ & $4.15(3.19)$ & $.173 * * *$ \\
\hline $15(\mathrm{n}=3283)$ & $5.99(3.57)$ & $.129 * * *$ & $4.21(3.06)$ & $.172 * * *$ \\
\hline \multicolumn{5}{|l|}{ Language region } \\
\hline German (n=23019) & $4.78(3.35)$ & reference & $3.04(2.87)$ & reference \\
\hline French $(\mathrm{n}=8266)$ & $5.54(3.77)$ & $.093 * * *$ & $3.13(3.02)$ & $.013 *$ \\
\hline Italian $(\mathrm{n}=2340)$ & $5.48(3.98)$ & $.051 * * *$ & $2.87(2.76)$ & $-.015 * *$ \\
\hline
\end{tabular}


Note: HBSC = Health Behaviour in School-aged Children; SD = standard deviation; ' sleep'; ' sum score of the items 'headache', 'backache', 'stomach ache' and 'dizziness'; ' sum scores range from 0 to 16 , whereby higher scores correspond to a higher symptom load; " $=\mathrm{p} \leq .05$; $^{* *}$ $=\mathrm{p} \leq .01 ;^{* * *}=\mathrm{p} \leq .001$ 